\section{"Tava morta e revivi": significado de maternidade para adolescentes com experiência de vida nas ruas}

\author{
"I was dead, but came back to life": the meaning \\ of motherhood for adolescent girls with a history \\ of living in the streets
}

\author{
${ }_{1}$ Departamento de Terapia \\ Ocupacional, Universidade \\ Católica de Goiás, Goiânia, \\ Brasil. \\ 2 Faculdade de Enfermagem \\ Universidade Federal de \\ Goiás, Goiânia, Brasil. \\ Correspondência \\ D. T. Gontijo \\ Departamento de Terapia \\ Ocupacional, Universidade \\ Católica de Goiás. \\ Rua 15 887, Goiânia, GO \\ 74150-120, Brasil. \\ danigontijo@hotmail.com \\ danielatgontijo@gmail.com
}

\begin{abstract}
The discovery of sexuality by adolescent girls living in the streets generally involves lack of knowledge about their own bodies, often resulting in risk behaviors for sexually transmitted diseases and pregnancy. This study aimed to identify the meanings ascribed to motherhood by teenage girls with a history of living in the streets and who chose to assume the care for their children, off the streets. Based on a qualitative methodology, data were collected from the adolescent mothers at a nongovernmental shelter and analyzed according to the content analysis modality. The results were discussed using the category "new life: mother \& child", showing that the adolescents ascribed a positive meaning to motherhood, with the child seen as both a "savior" from the mother's certain death on the streets and a repository for the mother's expectations for a better future. The article concludes by analyzing motherhood as an opportunity for establishing new ways of being in (and relating to) the world, with the construction of this motherhood process as a potentially fertile ground for intervention by health professionals.
\end{abstract}

Homeless Youth; Pregnancy in Adolescence; Life Change Events
Daniela T. Gontijo 1

Marcelo Medeiros 2

\section{Introdução}

No Brasil, muitas adolescentes provenientes de famílias marcadas pelo processo de exclusão social fazem das ruas seu espaço de sobrevivência 1 e descoberta da sexualidade. Geralmente introduzidas na vida sexual de forma violenta e precoce ${ }^{2}$, demonstram passividade diante desta submetendo-se aos acontecimentos na rua. Em meio ao desconhecimento do próprio corpo, desvencilham o sexo do desejo e prazer arriscando-se a contrair doenças sexualmente transmissíveis (DST/AIDS) e/ou a vivenciar a gravidez 3,4 .

Apesar da gravidez ser tradicionalmente caracterizada na Saúde Pública como "um problema" ou como "risco" para a adolescente e seu filho, atualmente estudos têm apontado controvérsias nestas concepções 5,6. Considerando esses aspectos, este estudo objetivou identificar o significado da maternidade para adolescentes-mães abrigadas, com experiência de rua.

Entendemos que este estudo detém um caráter transdisciplinar e contribui para o debate entre profissionais e responsáveis pela elaboração e implementação de políticas públicas, visando a melhorias da qualidade de vida de adolescentes e suas famílias em situação de risco social. 


\section{Percurso metodológico}

Pesquisa de abordagem qualitativa 7 realizada em uma "casa-lar", de caráter não-governamental, que abriga concomitantemente a adolescente com experiência de vida na rua e seu(s) filho(s). No período de coleta de dados, a instituição abrigava sete adolescentes das quais quatro, com idades de 17 a 23 anos e que se tornaram mães entre 15 e 17 anos, participaram do estudo.

Os dados foram coletados usando-se entrevistas semi-estruturadas, em que abordamos a experiência da gravidez na rua e o significado da maternidade. As entrevistas gravadas por meio digital foram transcritas e analisadas seguindo uma aproximação à análise de conteúdo, modalidade temática 8 , por meio da qual foram identificadas duas categorias temáticas. Neste texto analisamos de modo preliminar, a categoria " $a$ nova vida: mãe \& filho".

A pesquisa obteve aprovação do Juizado da Infância e Juventude do Estado de Goiás e do Comitê de Ética do Hospital das Clínicas da Universidade Federal de Goiás (parecer nº. 082/04).

\section{Resultados e discussão}

De modo geral, os relatos nos trazem a complexidade de ser adolescente, mãe, ex-menina de rua, mulher e abrigada, ao mesmo tempo. Durante as entrevistas, observamos diferentes reações das adolescentes, como hesitações, mudanças na expressão e postura corporal que revelaram uma maior dificuldade em falar de suas vidas no período anterior à vinda para o abrigo. Percebemos que esse período, marcado pelo processo de exclusão social de suas famílias, uso de drogas e a vivência de situações de extrema violência, faz parte de um passado que preferem não lembrar. Por outro lado, quando abordávamos a maternidade, a vida no abrigo ou as expectativas futuras, as adolescentes demonstravam uma maior disponibilidade para a conversa.

Para a maioria das adolescentes a gravidez não fora planejada, mas decorrente de relacionamentos pouco duradouros e de vínculos frágeis com o parceiro, fatos que refletiram na perda do contato com estes durante a gravidez e a não assunção em relação à paternidade, corroborando valores historicamente construídos em que o controle da contracepção e o cuidado das crianças são atribuídos às mulheres ${ }^{9}$.

Apesar de considerarem as dificuldades dessa decisão, as adolescentes de nosso estudo optaram por assumir seus filhos. Os primeiros cuidados, como amamentar e dar banho são permeados por sentimentos de insegurança e desconhecimento sobre os comportamentos do bebê e sobre as atitudes a serem tomadas, assim como também constatou Kreutz ${ }^{10}$. Nesses momentos, a ajuda de educadores do abrigo é reconhecida pelas adolescentes como de importância vital.

Ainda nessa situação, uma das entrevistadas faz referência ao processo de construção do vínculo afetivo com o filho, desmitificando a natureza instintiva do amor materno 11 , ao revelar que inicialmente percebia seu bebê como um desconhecido com o qual, aos poucos, foi construindo uma relação de afeto, tal como observamos no relato “...aí o tempo foi fazendo eu gostar dele” (E-1). Assim como observado em outros estudos 5,6,10, entendemos que a vivência da maternidade é percebida pela adolescente como um aumento da responsabilidade e como fator de amadurecimento.

As adolescentes, com o nascimento do filho, passam a estruturar a sua vida em torno das necessidades destes. As dificuldades nesse processo não podem ser atribuídas somente ao nascimento e cuidados necessários aos filhos, pois acostumadas a viver de acordo com o ritmo do próprio corpo e das ruas, que não se organiza com base em horários e rotinas, a vida no abrigo e o cuidado dos filhos, estruturados justamente com base nestes fatores, exigem um grande esforço de adaptação por parte das adolescentes deste estudo.

Por outro lado, podemos perceber como o papel de mãe possibilitou e possibilita a realização pessoal das adolescentes, que se mostram orgulhosas do desenvolvimento de seus filhos, e de serem reconhecidas por eles como mãe, sendo esta satisfação no exercício da maternidade também identificada por outros autores 5,6,12. No entanto, esses relacionam a satisfação de ser mãe apresentada pelas adolescentes muito mais ao aspecto de reconhecimento social do que o desempenho que este papel traz. Neste estudo, estamos percebendo que a satisfação das mães estava mais relacionada à formação de um vínculo de afeto genuíno com o filho.

Essa diferença na "fonte" de satisfação talvez possa ser atribuída às características diversas das amostras entre os estudos. Em sua maioria, os estudos sobre maternidade são realizados por meio de serviços de saúde 5 , com adolescentes que apesar de viveram em risco, apresentam a preservação de alguns dos vínculos sociais (família, escola, companheiro). Neste estudo, as adolescentes se caracterizam por vivenciarem um processo de ruptura intensa dos vínculos sociais, para as quais identificamos que a percepção de como se dá uma relação social baseada no afeto (mãe-filho) antecede a satisfação 
proveniente do reconhecimento social desta relação.

As adolescentes relatam o desejo de proporcionar para si e para os filhos oportunidades para a construção de um futuro melhor, sustentadas por uma maior escolaridade. Além disso, as adolescentes expressam claramente a esperança de que o filho não se envolva com a cultura da rua, pois o futuro na rua se resumiria à morte. É importante ressaltarmos que a possibilidade da construção de expectativas futuras para essas adolescentes está intimamente relacionada à ida para o abrigo, pois nas ruas elas "não pensavam em nada” (E-1), buscando a sobrevivência diariamente.

Finalmente, podemos ressaltar dois significados atribuídos pelas adolescentes aos filhos. $\mathrm{O}$ primeiro remete o filho à condição daquele que irá acabar com a solidão, com o abandono vivenciado pelas adolescentes. Esse significado se sustenta pela crença de uma relação duradoura, sendo o filho considerado a única forma de dar e receber amor, de forma genuína, conforme o depoimento de uma das entrevistadas afirmando que "de nenhuma outra pessoa a gente vai dar amor e receber amor, porque de outra pessoa (...). Não, a gente não sabe o que vem das outras pessoas" (E3).

O segundo significado atribuído ao filho foi a visão do filho como "salvador" de uma morte certa nas ruas, representando a possibilidade de construção de um futuro, que para acontecer implica a saída da adolescente do espaço da rua. Essa afirmação se apresenta em um dos relatos em que a adolescente afirma: "Ele [filho] veio pra mudar minha vida, se não fosse (...) eu acho que eu já tinha morrido" (E1).

\section{Algumas considerações}

De uma forma geral, pudemos perceber que a vivência da maternidade para estas adolescentes tem semelhanças com o que encontramos na literatura em relação às mães adolescentes de uma forma geral. No entanto, devemos pontuar algumas particularidades apresentadas pelas adolescentes de nosso estudo.

Consideramos que nos moldes no qual se estrutura esta instituição, a adolescente é estimulada a desvencilhar-se dos padrões de comportamento adotados anteriormente, e a construir juntamente com os educadores, as outras adolescentes e seus filhos novas formas de se relacionar e estar no mundo. Assumindo responsabilidade, aprendendo a desempenhar o papel materno, fazendo novas escolhas essas adolescentes continuam escrevendo a sua história de vida, agora, em um contexto, que lhes dá suporte na construção de sua independência e autonomia.

Ao possibilitar que a adolescente conviva com seu filho, este abrigo abre espaço para uma ruptura do círculo de quebras de vínculos que caracterizam suas vidas. A vivência da maternidade abre espaço para que elas se reconheçam e sejam reconhecidas com base nas suas capacidades como mãe, favorecendo a conquista ou resgate de sua auto-estima e configurando-se como um campo fértil para intervenção dos profissionais da saúde.

Enfim, a partir de nossas considerações não buscamos defender a ocorrência da gravidez na adolescência, no entanto, uma vez que ela aconteça, buscamos entendê-la do ponto de vista das adolescentes que a vivenciam, que muitas vezes não trazem a concepção de um acontecimento de "risco" e sim de uma experiência desejada, satisfatória e até mesmo salvadora. 


\section{Resumo}

A descoberta da sexualidade entre as adolescentes que fazem das ruas seu espaço de sobrevivência geralmente é permeada pelo desconhecimento do próprio corpo, o que resulta, muitas vezes, em comportamentos de risco para a contaminação por doenças sexualmente transmissíveis e para a gravidez. O objetivo desta pesquisa foi identificar os significados atribuídos à maternidade por adolescentes com experiência de vida nas ruas que optaram por assumir o cuidado dos filhos fora das ruas. Com base na abordagem de pesquisa qualitativa, os dados foram coletados junto a adolescentes-mães abrigadas em uma instituição não-governamental, $e$ analisados segundo a modalidade temática da análise de conteúdo. Os resultados foram discutidos por meio da categoria "a nova vida: mãe \& filho", mostrando que a experiência da maternidade é significada de forma positiva pelas adolescentes, sendo o filho entendido como o "salvador" de uma morte certa nas ruas, depositando nele as expectativas de um futuro melhor. A título de considerações finais, observamos no exercício da maternidade uma oportunidade de estabelecimento de novas formas de estar e se relacionar no mundo, sendo o processo de construção dessa maternidade terreno fértil para a intervenção de profissionais da saúde.

Menores de Rua; Gravidez na Adolescência; Acontecimentos que Mudam a Vida

\section{Referências}

1. Medeiros M. Olhando a lua pelo mundo da rua; representações sociais da experiência de vida de meninos em situação de rua [Tese de Doutorado]. Ribeirão Preto: Escola de Enfermagem de Ribeirão Preto, Universidade de São Paulo; 1999.

2. Drexel J, Ianone LR. Criança e miséria: vida ou morte. 9a Ed. São Paulo: Editora Moderna; 1994.

3. Fenelon GM, Martins LCH, Domingues MHMS. Meninas de rua: uma vida em movimento. Goiânia: Cegraf; 1992

4. Borges IK, Medeiros M. Representações sociais de DST/AIDS para adolescentes de uma instituição abrigo com experiência pregressa de vida nas ruas na cidade de Goiânia. DST J Bras Doenças Sex Transm 2004; 16:43-9.

5. Gontijo DT, Medeiros M. Gravidez/maternidade e adolescentes em situação de risco social e pessoal: algumas considerações. Rev Eletrônica Enferm 2004; 6:394-9.

6. Pantoja ALN. "Ser alguém na vida": uma análise sócio-antropológica da gravidez/maternidade na adolescência, em Belém do Pará, Brasil. Cad Saúde Pública 2003; 19 Suppl 2:S335-43.

\section{Colaboradores}

Ambos os autores contribuíram substancialmente para a concepção e design da proposta de pesquisa, assim como na coleta, análise e interpretação dos dados. Também foi conjunta a construção dos rascunhos e revisão crítica do texto.
7. Minayo MCS. O desafio do conhecimento: pesquisa qualitativa em saúde. 9a Ed. São Paulo: Editora Hucitec/Rio de Janeiro: ABRASCO; 2006.

8. Bardin L. Análise de conteúdo. Lisboa: Edições 70; 1979.

9. D'Oro ACDO. Investigação sobre a percepção de adolescentes acerca da sexualidade e fertilidade sob o enfoque de gênero [Tese de Doutorado]. São Paulo: Faculdade de Saúde Pública, Universidade de São Paulo; 2003.

10. Kreutz CM. A experiência da maternidade e a interação mãe-bebê em mães adolescentes e adultas [Dissertação de Mestrado]. Porto Alegre: Universidade Federal do Rio Grande do Sul; 2001.

11. Badinter E. Um amor conquistado: o mito do amor materno. 9a Ed. Rio de Janeiro: Editora Nova Fronteira; 1985

12. Hanna B. Negotiating motherhood: the struggles of teenage mothers. J Adv Nurs 2001; 34:456-64

Recebido em 08/Mar/2006

Versão final reapresentada em 10/Set/2007 Aprovado em 27/Set/2007 